\title{
Cerebral and skin microcirculatory dysfunction in type 1 diabetes
}

\author{
Grzegorz M. Kozera'1, Jolanta Neubauer-Geryk², Bogumił Wolnik³, Sebastian Szczyrba ${ }^{4}$, Joanna Wojczal ${ }^{5}$, \\ Walenty M. Nyka ${ }^{4}$, Leszek Bieniaszewski²
}

${ }^{1}$ Department of Neurology, Collegium Medicum in Bydgoszcz, Nicolaus Copernicus University in Torun, Poland ${ }^{2}$ Clinical Physiology Unit, Medical Simulation Centre, Medical University of Gdansk, Gdansk, Poland ${ }^{3}$ Department of Hypertension and Diabetology, Medical University of Gdansk, Gdansk, Poland ${ }^{4}$ Department of Neurology, Medical University of Gdansk, Gdansk, Poland ${ }^{5}$ Department of Neurology, Ultrasound Lab, Medical University of Lublin, Lublin, Poland

Adv Dermatol Allergol 2019; XXXVI (1): 44-50 DOI: https://doi.org/10.5114/ada.2018.81185

\begin{abstract}
Introduction: An increase in cerebral pulsatility index $(\mathrm{PI})$, measured by transcranial Doppler, reflects the presence of cerebral microangiopathy. A decrease in distance between skin capillaries (DISTANCE) and an increase in the ratio between the area of capillaries and total area of examined skin (COVERAGE), revealed by capillaroscopy, reflects skin microangiopathy. However, little is known about the association between the cerebral and skin microvasculature function in patients at risk of microcirculatory dysfunction.

Aim: To assess PI of the middle cerebral artery by transcranial Doppler and the DISTANCE and COVERAGE of the nailfold capillaries by quantitative capillaroscopy in patients with type 1 diabetes and control subjects without diabetes, and to investigate relationships between these parameters.

Material and methods: The study group consisted of 51 patients with type 1 diabetes (median age: 37.5 years) and 23 volunteers free from chronic diseases (median age: 37.9 years).

Results: Median PI was higher in patients than in control subjects ( 0.82 vs. $0.75 ; p<0.01)$. Median DISTANCE was lower in patients than in control subjects $(220.9 \mu \mathrm{m}$ vs. $239.7 \mu \mathrm{m} ; p=0.03)$, while median COVERAGE was higher in patients than in control subjects ( $20.4 \%$ vs. $18.3 \% ; p=0.01)$. No correlations between PI and DISTANCE or COVERAGE were found, but PI was correlated with patients' age and diabetes duration.

Conclusions: In spite of simultaneous presence of cerebral and skin microangiopathy, we found no association between cerebral and skin microvasculature dysfunction. This seems to indicate independent progression of microcirculatory injury in cerebral and peripheral vascular beds.
\end{abstract}

Key words: type 1 diabetes, microangiopathy, transcranial Doppler, cerebral pulsatility capillaroscopy.

\section{Introduction}

Transcranial Doppler (TCD) is an ultrasound technique for noninvasive assessment of cerebral circulatory function. Cerebral pulsatility index (PI) is a TCD parameter that reflects the elasticity of cerebral microcirculation [1]. Its increase is regarded as a marker of both symptomatic and asymptomatic cerebral microangiopathy [2-4].

Skin microcirculation may be noninvasively assessed by capillaroscopy with measurement of the distance between capillaries in the nailfold (DISTANCE) and the ratio between the area of capillaries and total area of examined skin (COVERAGE) [5]. A decrease in DISTANCE and an increase in COVERAGE may indicate skin microcirculatory dysfunction [6]

Patients with type 1 diabetes are at high risk of early development of both cerebral and skin microvascular injury. Previous reports revealed the presence of cerebral microangiopathy in young patients with type 1 diabetes, reflected increased vasomotor reactivity impairment [7-9]. However, an increase in PI has been reported only in middle-aged patients with type 1 diabetes and in patients with type 2 diabetes [9-11].

Our recent study on skin capillary function has revealed the presence of skin microangiopathy in young patients with type 1 diabetes [6]. However, little is known

Address for correspondence: Grzegorz M. Kozera, Department of Neurology, Collegium Medicum, Nicolaus Copernicus University, 9 Skłodowskiej-Curie St, 85-920 Bydgoszcz, Poland, phone: +48 5258540 32, e-mail: gkozera@cm.umk.pl Received: 30.11.2017, accepted: 8.01.2018. 
about the association between cerebral and skin microvasculature function in those patients with type 1 diabetes. Thus, it remains unclear if the detection of skin microangiopathy may predict the presence of microvascular impairment in other vascular beds, especially cerebral microangiopathy.

\section{Aim}

The aim of the study was to assess PI of the middle cerebral artery by TCD measurements as well as the DISTANCE and COVERAGE of the nailfold capillaries by quantitative capillaroscopy in young patients with type 1 diabetes and control subjects without diabetes, and to assess the relationship between those parameters and the presence of other microangiopathic disorders.

\section{Material and methods}

The study group consisted of 51 patients with type 1 diabetes (28 women and 23 men; median age: 37.5 years), recruited from the Regional Diabetological Centre of the Medical University of Gdansk, and 23 volunteers without diabetes (11 women and 12 men; median age: 37.9 years) (Table 1). We included patients free of focal neurologic deficits, with minimum diabetes duration of 6 years. We excluded subjects with a history of cerebrovascular events or serious head trauma, significant stenosis or occlusion of extracranial arteries, renal insufficiency, those with previously diagnosed rheumatologic diseases, and pregnant females. We also excluded control subjects with arterial hypertension, proteinuria, and impaired glucose tolerance.

All examinations were performed at the same time of day (between 8:00 A.M. and 1:00 P.M.). All study subjects were asked to stop drinking coffee and to stop smoking tobacco on the examination day and to avoid sleep deprivation on previous days. The study protocol included medical history, neurologic examination, fundoscopy, laboratory testing, carotid and transcranial Doppler, and capillaroscopy. The Medical Ethics Committee of the Medical University of Gdansk has approved the study protocols (NKEBN/335/2008, NKEBN/204/2010). On entry to the study, each participant gave informed consent.

Table 1. Characteristics of patients with type 1 diabetes and control subjects

\begin{tabular}{|c|c|c|c|}
\hline \multirow[t]{2}{*}{ Parameter } & \multicolumn{2}{|c|}{ Group } & \multirow[t]{2}{*}{$P$-value } \\
\hline & $\begin{array}{l}\text { Patients } \\
(n=51)\end{array}$ & $\begin{array}{l}\text { Control } \\
(n=23)\end{array}$ & \\
\hline Age [years] & $37.5(29.9-55.7)$ & $37.9(26.3-51.3)$ & 0.64 \\
\hline $\mathrm{F}: \mathrm{M}$ ratio & $28: 23$ & $11: 12$ & $\begin{array}{c}0.57 \\
\chi^{2}=0.32\end{array}$ \\
\hline $\mathrm{BMI}\left[\mathrm{kg} / \mathrm{m}^{2}\right]$ & $24.9(19.0-37.3)$ & $24.0(20.1-33.3)$ & 0.61 \\
\hline Systolic blood pressure [mm Hg] & $134.0 \pm 20.2$ & $128.5 \pm 21.6$ & 0.29 \\
\hline Diastolic blood pressure [mm Hg] & $66.0(45-120)$ & $70(45-113)$ & 0.71 \\
\hline Hyperlipidemia (\%) & 80.4 & 82.6 & $\begin{array}{c}0.82 \\
\chi^{2}=0.05\end{array}$ \\
\hline Cigarette smoking (\%) & 23.5 & 8.7 & $\begin{array}{c}0.13 \\
\chi^{2}=2.3\end{array}$ \\
\hline Overweight or obesity (\%) & 49.0 & 39.1 & $\begin{array}{c}0.43 \\
\chi^{2}=0.63\end{array}$ \\
\hline Statin treatment (\%) & 21.6 & 4.3 & $\begin{array}{c}0.06 \\
\chi^{2}=3.5\end{array}$ \\
\hline Diabetic nephropathy (\%) & 31.4 & n.a. & n.a. \\
\hline Diabetic retinopathy (\%) & 47.1 & n.a. & n.a. \\
\hline Diabetic neuropathy (\%) & 49.0 & n.a. & n.a. \\
\hline Type 1 diabetes duration [years] & $20.5 \pm 6.5$ & n.a. & n.a. \\
\hline $\begin{array}{l}\mathrm{HbA}_{1 \mathrm{c}}(\%) \\
{[\mathrm{mmol} / \mathrm{mol}]}\end{array}$ & $\begin{array}{c}7.92 \pm 1.2 \\
63\end{array}$ & n.a. & n.a. \\
\hline Circadian insulin demand [units] & $56.7 \pm 16.5$ & n.a. & n.a. \\
\hline Arterial hypertension (\%) & 23.5 & n.a. & n.a. \\
\hline ACEI or ARB treatment (\%) & 17.6 & n.a. & n.a. \\
\hline
\end{tabular}

$F: M$ ratio - female to male ratio, $B M I$ - body mass index, $H b A_{1 c}$ - glycated hemoglobin, ACEl - angiotensin-converting enzyme inhibitor, $A R B$ - angiotensin receptor blocker, n.a. - not applicable 


\section{Subject characteristics}

Patient histories were obtained, including information on past and current disorders as well as co-morbid conditions and cigarette smoking. Weight and height were measured and body mass index (BMI) was calculated. Overweight and obesity were defined as BMI $>25 \mathrm{~kg} / \mathrm{m}^{2}$ and $\mathrm{BMI}>30 \mathrm{~kg} / \mathrm{m}^{2}$, respectively. Blood pressure control in all subjects was monitored by conventional sphygmomanometry. Arterial hypertension was diagnosed if two consecutive measurements of systolic and diastolic blood pressures exceeded 140 and $90 \mathrm{~mm} \mathrm{Hg}$, respectively, or if any antihypertensive medication was used.

Laboratory examinations in patients with type 1 diabetes included microalbuminuria, albuminuria/creatinine index, total serum cholesterol, low-density lipoprotein (LDL) cholesterol, high-density lipoprotein (HDL) cholesterol, triglycerides, and glycated hemoglobin $\left(\mathrm{HbA}_{1 \mathrm{c}}\right)$. Blood and urine samples were collected on the day of the examination. The assessment of albumin secretion was based on 3 measurements that were closest in time to the study.

Hyperlipidemia was diagnosed if total cholesterol was $>175 \mathrm{mg} / \mathrm{dl}$ and/or triglycerides were $>150 \mathrm{mg} / \mathrm{dl}$ and/or LDL cholesterol was $>100$ mg/dl. Hyperlipidemia was also diagnosed if the HDL level was $<40 \mathrm{mg} / \mathrm{dl}$ in males or $>50 \mathrm{mg} / \mathrm{dl}$ in females, or if cholesterol-lowering/triglyceride-lowering medications were used [12]. In the control group, hyperlipidemia was diagnosed if total cholesterol and/or triglycerides and/or LDL cholesterol exceeded 190, 150, and $130 \mathrm{mg} / \mathrm{dl}$, respectively, or if the $\mathrm{HDL}$ level was $<40 \mathrm{mg} / \mathrm{dl}$ in males or $>50 \mathrm{mg} / \mathrm{dl}$ in $\mathrm{fe}$ males [13].

Diabetic nephropathy was diagnosed on the basis of presence of microalbuminuria or overt nephropathy. Based on the criteria of the European Association for the Study of Diabetes, microalbuminuria was defined as the albuminuria/creatinine index in a random spot collection (> $30 \mathrm{mg} / \mathrm{mg}$ creatinine) or overnight collection $(<20 \mathrm{mg} / \mathrm{min})$ in two out of three urine collections repeated at intervals of up to 6 months [12].

Retinopathy was recognized on fundoscopy performed by an ophthalmologist certified by the Polish Ophthalmological Society. Retinopathy was graded according to the stages of diabetic retinopathy defined by the American Academy of Ophthalmology [14]. Previous therapy with photocoagulation was also recognized as a marker of diabetic retinopathy.

Diabetic neuropathy was diagnosed using the criteria defined by the Neurologic Symptom Score and Neurologic Disability Score, based on patient symptoms and neuropathic deficits found on neurologic examination [15].

\section{Carotid Doppler examination}

Standard examinations of both carotid arteries were performed before TCD measurements using a Vivid i ultrasound machine (GE Healthcare, USA) equipped with a linear probe with a central working frequency of 6.3 $\mathrm{MHz}$ and range limits of 3.9-8.4 MHz, performed by a well-trained investigator (GK, with 11 years of experience). The protocol of the carotid duplex examination consisted of standard measurement of intima-media complex, assessment of the presence, echogenicity and size of atheromatous plaques and measurements of systolic and diastolic velocities in both common carotid and extracranial internal carotid arteries to exclude their occlusion or $>50 \%$ carotid stenosis. The degree of stenosis was measured according to von Reutern's criteria [16].

\section{Transcranial Doppler examination}

Middle cerebral artery flow parameters were measured by TCD through the temporal bone window, using a MultiDop T2 DWL device (DWL Elektronische Systeme, Singen, Germany) equipped with a hand-held $2-\mathrm{MHz}$ PW probe. Flow measurements were performed in both middle cerebral arteries by a single, well-trained ultrasonographer (GK). Measurements were performed in supine position after 10 min of rest. During the test, the $\mathrm{CO}_{2}$ content of expired air (end-tidal $\mathrm{CO}_{2}$ concentration) was monitored continuously (capnograph, Datex Normocap, Helsinki, Finland). Before the tests, the systemic blood pressure was measured. Median values of arithmetic means of velocity measurements at rest (Vmean) and PI from both middle cerebral arteries were used for further off-line analyses.

\section{Capillaroscopy}

Subjects participating in the study were asked not to dispatch the skin of their fingernails for at least 2 weeks before the start of the study. During examination, patients remained in a comfortable sitting position, with the hand conveniently supported and laid stably under the capillaroscope. Tags were drawn on their nail folds to establish areas for calculation. The room temperature was controlled by air conditioning and was kept the same during all tests. Body temperature was controlled with the use of a contactless thermometer and was within normal range in all examined patients and control subjects [6].

The skin capillaries were examined by a stereomicroscope with a point light source. The nailfold capillaries were made transparent by adding a drop of immersion oil. Images were taken using a digital camera (5MPx; OPTA-TECH, Warsaw, Poland) attached to the capillaroscope, with a lens providing a magnification of 200x (OPTA-TECH, CS-CREATIVE SOLUTIONS Group, Warsaw, Poland) and archived on a disc. The image analysis was performed off-line, semiautomatic with dedicated software [17].

Off-line computer analysis included the following steps: rotation of the image; selection of the part of the 
image for further analysis; tuning the process of selected area; recognition of capillaries; and final acceptance of results. The first two rows of capillaries in the nail fold were evaluated. The images with less than five capillaries in each row were not considered for statistical analysis. The image analysis allows determination of the mean distance between capillaries (DISTANCE) and the ratio between the area of capillaries and total area of examined skin (COVERAGE) [6].

\section{Statistical analysis}

All the analyses were performed with Statistica version 9.1 software (StatSoft Inc, Tusla, OK). Shapiro-Wilk tests were performed to analyze the distribution of continuous variables. Differences between groups were analyzed with Student's t-test for normally distributed variables (circadian insulin demand) or with the MannWhitney $U$ test for the other variables (age, type 1 diabetes duration, BMI, diastolic and systolic blood pressure, Vmean, PI, DISTANCE and COVERAGE, and end-tidal $\mathrm{CO}_{2}$ concentration). The $\chi^{2}$ test was used to compare the female to male ratio, the prevalence of systemic microvascular complications, and concomitant risk factors in groups. The correlation was assessed by the Spearman rank correlation test. The level of $p<0.05$ was regarded as statistically significant.

\section{Results}

Based on medical history, physical examination, biochemical analysis, carotid and transcranial ultrasound, none of the study subjects had an established diagnosis of coronary heart disease, diabetic foot, orthostatic hypotension, chronic renal insufficiency or significant stenosis (> 50\%) of the extra- and intracranial arteries. The two compared groups (patients with type 1 diabetes and control subjects) did not differ in terms of age, gender, body mass index (BMI), systolic and diastolic blood pressure, cigarette smoking, and co-morbidities or treatments (Table 1 ).
Median PI was higher in patients with type 1 diabetes than in control subjects. Median DISTANCE was lower in the patients and median COVERAGE was higher in the patients than in the control group. We found no significant differences in Vmean, mean arterial pressure, and end-tidal $\mathrm{CO}_{2}$ between the groups (Table 2). No differences in PI, COVERAGE and DISTANCE were detected between subgroups of patients with type 1 diabetes divided on the basis of presence/absence of vascular risk factors, co-morbidities, and treatments (Table 3).

We found significant, positive correlations between PI and both age and diabetes duration in patients with type 1 diabetes, but no correlation between PI and age in control subjects. There were no correlations between PI and DISTANCE or COVERAGE in patients with type 1 diabetes and the control group. No correlations were found also between $\mathrm{PI}$ and $\mathrm{BMI}$, both in patients and control subjects, and between $\mathrm{Pl}$ and glycated hemoglobin $\left(\mathrm{HbA}_{1 \mathrm{c}}\right)$ or circadian insulin demand in patients with type 1 diabetes (Table 4).

\section{Discussion}

Our study demonstrated that PI of the middle cerebral artery in young patients with type 1 diabetes is higher than in control subjects without diabetes. We also revealed that the distance between skin capillaries is lower in patients than in control subjects, and coverage of capillaries in the nail fold is higher in diabetic patients than in the control group. We found a significant correlation between patient age and PI, but we have not found any other associations between cerebral PI, skin microcirculatory parameters and other risk factors or concomitant diseases, both in patients and control subjects. Thus, we did not confirm the correlation between cerebral and skin microcirculatory impairment in both groups.

A majority of previous reports that revealed increased PI in diabetic subjects, focused on type 2 diabetes [4, 10, 11]. Cerebral PI in type 1 diabetes has been rarely evaluated so far. A report presented by Siro et al. showed an increase in $\mathrm{PI}$ in middle-aged patients with type 1 diabe-

Table 2. Comparison of middle cerebral artery blood flow parameters and capillaroscopy findings between patients with type 1 diabetes and healthy control subjects

\begin{tabular}{lccc}
\hline Parameter & $\begin{array}{c}\text { Patients } \\
(n=51)\end{array}$ & $\begin{array}{c}\text { Control group } \\
(n=23)\end{array}$ & $P$-value \\
\hline Vmean $[\mathrm{cm} / \mathrm{s}]$ & $66.8 \pm 16.2$ & $65.5 \pm 14.1$ & 0.73 \\
\hline Pulsatility index & $0.82(0.65-1.19)$ & $0.75(0.60-1.07)$ & $<0.01$ \\
\hline DISTANCE $[\mu \mathrm{m}]$ & $220.9(152.6-311.0)$ & $239.7(184.8-356.2)$ & 0.03 \\
\hline COVERAGE $(\%)$ & $20.4 \pm 3.5$ & $18.3 \pm 2.8$ & 0.01 \\
\hline End-tidal $\mathrm{CO}_{2}(\%)$ & $4.77 \pm 0.5$ & $4.8 \pm 0.5$ & 0.76 \\
\hline Mean arterial pressure $[\mathrm{mm} \mathrm{Hg}]$ & $87.7(61.0-140.0)$ & $90.3(61.6-138.3)$ & 0.98 \\
\hline
\end{tabular}

Vmean - mean flow velocity in middle cerebral artery, DISTANCE - distance between skin capillaries, COVERAGE - ratio between the area of capillaries and total area of examined skin. 
Table 3. Values of pulsatility index, COVERAGE, and DISTANCE in subgroups of patients with type 1 diabetes divided on the basis of presence/absence of vascular risk factors, co-morbidities, and treatments

\begin{tabular}{|c|c|c|c|c|c|c|c|c|c|}
\hline \multirow[t]{2}{*}{ Factor } & \multicolumn{3}{|c|}{ Pulsatility index } & \multicolumn{3}{|c|}{ DISTANCE $[\mu \mathrm{m}]$} & \multicolumn{3}{|c|}{ COVERAGE [\%] } \\
\hline & Present & Absent & $P$-value & Present & Absent & $P$-value & Present & Absent & $P$-value \\
\hline $\begin{array}{l}\text { Hyperlipidemia } \\
(n=41)\end{array}$ & $\begin{array}{c}0.82 \\
(0.65-1.14)\end{array}$ & $\begin{array}{c}0.85 \\
(0.66-1.19)\end{array}$ & 0.73 & $\begin{array}{c}220.6 \\
(152.6-311.0)\end{array}$ & $\begin{array}{c}222.8 \\
(186.0-255.6)\end{array}$ & 0.82 & $\begin{array}{l}20.2 \\
\pm 3.7\end{array}$ & $\begin{array}{l}21.0 \\
\pm 2.8\end{array}$ & 0.56 \\
\hline $\begin{array}{l}\text { Hypertension } \\
(n=12)\end{array}$ & $\begin{array}{c}0.91 \\
(0.71-1.19)\end{array}$ & $\begin{array}{c}0.82 \\
(0.65-1.11)\end{array}$ & 0.10 & $\begin{array}{c}226.5 \\
(178.7-311.0)\end{array}$ & $\begin{array}{c}22.6 \\
(152.6-304.7)\end{array}$ & 0.75 & $\begin{array}{l}20.4 \\
\pm 3.5\end{array}$ & $\begin{array}{l}20.4 \\
\pm 3.7\end{array}$ & 0.99 \\
\hline $\begin{array}{l}\text { Neuropathy } \\
(n=25)\end{array}$ & $\begin{array}{c}0.87 \\
(0.65-1.19)\end{array}$ & $\begin{array}{c}0.81 \\
(0.65-1.09)\end{array}$ & 0.09 & $\begin{array}{c}220.6 \\
(152.3-311.0)\end{array}$ & $\begin{array}{c}221.0 \\
(171.2-284.9)\end{array}$ & 0.97 & $\begin{array}{r}20.5 \\
\pm 3.3\end{array}$ & $\begin{array}{l}20.1 \\
\pm 3.7\end{array}$ & 0.48 \\
\hline $\begin{array}{l}\text { Retinopathy } \\
(n=24)\end{array}$ & $\begin{array}{c}0.85 \\
(0.65-1.19)\end{array}$ & $\begin{array}{c}0.82 \\
(0.65-1.1)\end{array}$ & 0.85 & $\begin{array}{c}223.3 \\
(178.7-311.0)\end{array}$ & $\begin{array}{c}219.6 \\
(152.6-280.9)\end{array}$ & 0.61 & $\begin{array}{l}20.8 \\
\pm 4.2\end{array}$ & $\begin{array}{l}20.1 \\
\pm 2.9\end{array}$ & 0.46 \\
\hline $\begin{array}{l}\text { Nephropathy } \\
(n=16)\end{array}$ & $\begin{array}{c}0.81 \\
(0.71-1.19)\end{array}$ & $\begin{array}{c}0,86 \\
(0.65-1.14)\end{array}$ & 0.76 & $\begin{array}{c}223.3 \\
(152.6-304.7)\end{array}$ & $\begin{array}{c}215.6 \\
(171.2-311.0)\end{array}$ & 0.41 & $\begin{array}{l}19.8 \\
\pm 3.3\end{array}$ & $\begin{array}{l}20.7 \\
\pm 3.7\end{array}$ & 0.38 \\
\hline $\begin{array}{l}\text { ACEI or ARB } \\
\text { treatment } \\
(n=9)\end{array}$ & $\begin{array}{c}0.89 \\
(0.71-1.19)\end{array}$ & $\begin{array}{c}0.82 \\
(0.65-1.11)\end{array}$ & 0.15 & $\begin{array}{c}225.3 \\
(186.0-311.1)\end{array}$ & $\begin{array}{c}220.7 \\
(152.6-304.7)\end{array}$ & 0.68 & $\begin{array}{l}20.1 \\
\pm 3.4\end{array}$ & $\begin{array}{l}20.5 \\
\pm 3.6\end{array}$ & 0.75 \\
\hline $\begin{array}{l}\text { Statin treatment } \\
(n=11)\end{array}$ & $\begin{array}{c}0.93 \\
(0.71-1.19)\end{array}$ & $\begin{array}{c}0.81 \\
(0.65-1.11)\end{array}$ & 0.06 & $\begin{array}{c}227.6 \\
(178.8-311.1)\end{array}$ & $\begin{array}{c}217.6 \\
(152.6-304.7)\end{array}$ & 0.46 & $\begin{array}{l}20.1 \\
\pm 3.4\end{array}$ & $\begin{array}{l}20.5 \\
\pm 3.4\end{array}$ & 0.76 \\
\hline $\begin{array}{l}\text { Overweight or } \\
\text { obesity }(n=25)\end{array}$ & $\begin{array}{c}0.86 \\
(0.65-1.19)\end{array}$ & $\begin{array}{c}0.82 \\
(0.66-1.14)\end{array}$ & 0.25 & $\begin{array}{c}220.9 \\
(178.8-304.7)\end{array}$ & $\begin{array}{c}220.4 \\
(152.6-311.1)\end{array}$ & 0.89 & $\begin{array}{l}20.5 \\
\pm 3.5\end{array}$ & $\begin{array}{l}20.3 \\
\pm 3.7\end{array}$ & 0.90 \\
\hline $\begin{array}{l}\text { Cigarette smoking } \\
(n=12)\end{array}$ & $\begin{array}{c}0.82 \\
(0.70-1.09)\end{array}$ & $\begin{array}{c}0.83 \\
(0.65-1.19)\end{array}$ & 0.95 & $\begin{array}{c}221.0 \\
(152.6-280.4)\end{array}$ & $\begin{array}{c}220.6 \\
(171.2-311.0)\end{array}$ & 0.60 & $\begin{array}{r}21.6 \\
\pm 3.2\end{array}$ & $\begin{array}{l}20.0 \\
\pm 3.6\end{array}$ & 0.16 \\
\hline
\end{tabular}

DISTANCE - distance between skin capillaries, COVERAGE - ratio between the area of capillaries and total area of examined skin, ACEI - angiotensin-converting enzyme inhibitor, $A B R$ - angiotensin receptor blocker.

Table 4. Analysis of correlations between the pulsatility index, COVERAGE, and DISTANCE in patients with type 1 diabetes and control subjects

\begin{tabular}{lcc}
\hline Parameter & \multicolumn{1}{c}{ Correlations for the pulsatility index } \\
\cline { 2 - 3 } & $\begin{array}{c}\text { Patients } \\
(n=51)\end{array}$ & $\begin{array}{c}\text { Control group } \\
(n=23)\end{array}$ \\
\hline DISTANCE $[\mu \mathrm{m}]$ & $r=0.13, p=0.34$ & $r=-0.1, p=0.63$ \\
\hline COVERAGE $(\%)$ & $r=-0.07, p=0.60$ & $r=0.10, p=0.64$ \\
\hline Age $[$ years] & $r=0.34, p=0.01$ & $r=-0.11, p=0.60$ \\
\hline BMI $\left[\mathrm{kg} / \mathrm{m}^{2}\right]$ & $r=0.21, p=0.14$ & $r=-0.34, p=0.11$ \\
\hline Smoking load [pack-years] & $r=-0.04, p=0.89$ & n.a. \\
\hline Type 1 diabetes duration [years] & $r=0.40, p=0.003$ & n.a. \\
\hline HbA $_{1 \mathrm{lc}}(\%)$ & $r=-0.19, p=0.18$ & n.a. \\
\hline Circadian insulin demand [units] & $r=-0.12, p=0.37$ & n.a. \\
\hline
\end{tabular}

Vmean - mean flow velocity in middle cerebral artery, DISTANCE - distance between skin capillaries, COVERAGE - ratio between the area of capillaries and total area of examined skin, $B M I$ - body mass index, $\mathrm{HbA}_{I c}$ - glycated hemoglobin, n.a. - not applicable.

tes [9]. On the other hand, our previous report, concerning young patients with type 1 diabetes, did not reveal any increase in cerebral PI in this type of diabetes [7]. The present study shows a PI increase in patients with type 1 diabetes below 40 years of age. This finding, and the positive correlation between PI and patient age, which is not present in the control group, support the hypothesis of faster development of cerebral microangiopathy in patients with type 1 diabetes. These results are also consis- tent with previous reports that showed an association of patient age or disease duration and PI in type 2 diabetes $[4,10]$. Thus we can suggest the trigger effect of type 1 diabetes on the extent of cerebral microangiopathy.

The influence of type 1 diabetes on skin microcirculation is still an open question. Kuryliszyn-Moskal et al. detected skin microangiopathy in $81 \%$ of patients with type 1 diabetes [18]. Tibriça et al. showed impaired skin microcirculation in patients with this type of diabetes 
[19]. Our recent study also revealed skin microcirculatory dysfunction, which was related to late onset of type 1 diabetes [6]. However, both Meyer et al. and Trapp et al. demonstrated no difference in density, diameter, and morphology of capillaries between diabetic patients and control subjects without diabetes [20, 21]. Likewise, Gasser and Berger found no differences between healthy subjects and patients in nailfold videocapillaroscopy at rest and after local cooling [22]. Results of the present study are in line with those reports that show skin microcirculatory impairment in patients with type 1 diabetes.

Similarly, the relationship between the presence of microangiopathy in the skin and other vascular beds is not clear. Studies of Jörneskog et al. reported that skin microangiopathy in diabetic patients occurs despite the existence of other microvascular diabetic complications and mainly metabolic control is of importance for the nutritive capillary circulation [23, 24]. Trapp et al. also found no correlation between morphology and density of capillaries and the presence of diabetic retinopathy [21]. Our findings are in line with those reports. However, Kuryliszyn-Moskal et al. showed an association between the severity of changes in capillary structure and the presence of chronic complications of type 1 diabetes [18]. Chang et al. suggested that changes in the retina are similar to those detected by capillaroscopy [25]. Urban et al. and Lefrandt et al. suggested that the presence of autonomic neuropathy significantly affects the skin microvascular function [26, 27]. Maldonado et al. showed that the patients with more comorbidities and evolution of the disease had greater microvascular damage [28].

To date it has remained unclear if the detection of skin microcirculatory dysfunction could indicate the presence of cerebral microangiopathy. Our results do not confirm the association between skin microvasculature and cerebral microcirculation functions in patients with type 1 diabetes. This may support the hypothesis that the extent of microcirculation disturbances may differ according to the nature of endothelial injury and may depend on intrinsic properties of the endothelium, especially due to different endothelial activity in cerebral and peripheral microcirculation [29]. It is also in line with former reports showing different effects of chronic diabetes on vascular responses in cerebral and peripheral vessels [30, 31].

However, previous reports on cerebral microvasculature in young patients with type 1 diabetes revealed an association between kidney or retinal microangiopathy and the presence of cerebral microvascular impairment $[7,32]$. Our results show a lack of such an association in older populations. In our opinion, this may indicate that the relationship between microvascular injury in different vascular beds is not fixed and can be affected by patient age, diabetes duration, and other factors.

Our results do not reveal any associations between concomitant diseases or vascular risk factors. This is in line with previous reports, concerning both cerebral and skin microvascular beds [6, 7]. Interestingly, in contrast to previous studies, we did not find any impact of use of angiotensin-converting enzyme inhibitors, angiotensin receptor blocker or statins on microcirculatory function $[33,34]$.

Our results are also limited by other factors. In our opinion, the most important is the high presence of hyperlipidemia in control subjects without frequent statin use, which can also influence cerebral microcirculation $[34,35]$. Besides, we realize that functional assessment of cerebral microcirculation by PI measurements does not fully reflect cerebral microcirculatory injury in type 1 diabetes. Morphological assessment, especially detection of white matter lesions and silent cerebral infarct by brain magnetic resonance imaging would extend our knowledge about cerebral microvasculature in those patients $[36,37]$.

\section{Conclusions}

In spite of simultaneous presence of cerebral microangiopathy (reflected by increased PI of the middle cerebral artery) and skin microangiopathy (reflected in by decreased DISTANCE and increased COVERAGE of skin capillaries), we found no significant association between cerebral and skin microvasculature function. This may indicate independent development of microcirculatory impairment in cerebral and peripheral vascular beds.

\section{Conflict of interest}

The authors declare no conflict of interest.

\section{References}

1. Kidwell CS, el-Saden S, Livshits Z, et al. Transcranial Doppler pulsatility indices as a measure of diffuse small-vessel disease. J Neuroimaging 2001; 11: 229-35.

2. Mok V, Ding D, Fu J, et al. Transcranial Doppler ultrasound for screening cerebral small vessel disease: a community study. Stroke 2012; 43: 2791-3.

3. Webb AJ, Simoni M, Mazzucco S, et al. Increased cerebral arterial pulsatility in patients with leukoaraiosis: arterial stiffness enhances transmission of aortic pulsatility. Stroke 2012; 43: 2631-6.

4. Lee KY, Sohn YH, Baik JS, Kim GW, Kim JS. Arterial pulsatility as an index of cerebral microangiopathy in diabetes. Stroke 2000; 31: 1111-5.

5. Abi-Chahin TC, Hausen Mde A, Mansano-Marques CM, Halfoun VL. Microvascular reactivity in type 1 diabetics. Arq Bras Endocrinol Metabol 2009; 53: 741-6.

6. Neubauer-Geryk J, Kozera GM, Wolnik B, et al. Decreased reactivity of skin microcirculation in response to $L$-arginine in later-onset type 1 diabetes. Diabetes Care 2013; 36: 950-6.

7. Kozera GM, Wolnik B, Kunicka KB, et al. Cerebrovascular reactivity, intima-media thickness, and nephropathy presence in patients with type 1 diabetes. Diabetes Care 2009; 32: 878-82. 
8. Fülesdi B, Limburg M, Bereczki D, et al. Impairment of cerebrovascular reactivity in long-term type 1 diabetes. Diabetes 1997; 46: 1840-5.

9. Siro P, Molnar C, Katona E, et al. Carotid intima-media thickness and cerebrovascular reactivity in long-term type 1 diabetes mellitus. J Clin Ultrasound 2009; 37: 451-6.

10. Park JS, Cho MH, Lee KY, et al. Cerebral arterial pulsatility and insulin resistance in type 2 diabetic patients. Diabetes Res Clin Pract 2008; 79: 237-42.

11. Lee KO, Lee KY, Lee SY, et al. Lacunar infarction in type 2 diabetes is associated with an elevated intracranial arterial pulsatility index. Yonsei Med J 2007; 48: 802-6.

12. American Diabetes Association. Standards of medical care in diabetes - 2010. Diabetes Care 2010; 33 Suppl 1: S11-61.

13. Institute for Clinical Systems Improvement. Lipid management in adults. $12^{\text {th }}$ edition. Available from http://www.icsi. org, accessed 12 December 2013.

14. Singer DE, Nathan DM, Fogel HA, Schachat AP. Screening guidelines for diabetic retinopathy. Ann Intern Med 1992; 116: 660-71.

15. Dyck PJ. Detection, characterization, and staging of polyneuropathy: assessed in diabetics. Muscle Nerve 1988; 11: 21-32.

16. von Reutern GM, Goertler MW, Bornstein NM, et al. Grading carotid stenosis using ultrasonic methods. Stroke 2012; 43: 916-21.

17. Iaremko M. Identyfikacja i ocena gestości naczyń włosowatych na podstawie obrazów mikroskopowych. Politechnika Gdańska. Wydział Fizyki Stosowanej. 2011; Thesis 1-28.

18. Kuryliszyn-Moskal A, Ciołkiewicz M, Dubicki A. Morphological alterations in nailfold capillaroscopy and the clinical picture of vascular involvement in autoimmune diseases: sys temic lupus erythematosus and type 1 diabetes. Ann Acad Med Stetin 2010; 56 Suppl 1: 73-9.

19. Tibiriça E, Rodrigues E, Cobas RA, Gomes MB. Endothelial function in patients with type 1 diabetes evaluated by skin capillary recruitment. Microvasc Res 2007; 73: 107-12.

20. Meyer MF, Pfohl M, Schatz H. Assessment of microcirculatory alterations in diabetic patients by means of capillaroscopy and laser Doppler anemometry. Med Klin 2001; 96: 71-7.

21. Trapp RG, Soler NG, Spencer-Green G. Nailfold capillaroscopy in type 1 diabetics with vasculopathy and limited joint mobility. J Rheumatol 1986; 13: 917-20.

22. Gasser P, Berger W. Nailfold video-microscopy and local cold test in type 1 diabetics. Angiology 1992; 43: 395-400.

23. Jörneskog G, Brismar K, Fagrell B. Skin capillary circulation severely impaired in toes of patients with IDDM, with and without late diabetic complications. Diabetologia 1995; 38: 474-80.

24. Jörneskog G, Brismar K, Fagrell B. Pronounced skin capillary ischemia in the feet of diabetic patients with bad metabolic control. Diabetologia 1998; 41: 410-5.

25. Chang CH, Tsai RK, Wu WC, et al. Use of dynamic capillaroscopy for studying cutaneous microcirculation in patients with diabetes mellitus. Microvasc Res 1997; 53: 121-7.

26. Urban M, Peczyńska J, Kowalewski M, Głowińska-Olszewska B. Does autonomic diabetic neuropathy influence microcirculation reactivity in adolescents with diabetes type 1? Endokrynol Diabetol Chor Przemiany Materii Wieku Rozw 2007; 13: 23-6.

27. Lefrandt JD, Bosma E, Oomen PH, et al. Sympathetic mediated vasomotion and skin capillary permeability in diabetic patients with peripheral neuropathy. Diabetologia 2003; 46 40-7.
28. Maldonado G, Guerrero R, Paredes C, Ríos C. Nailfold capillaroscopy in diabetes mellitus. Microvasc Res 2017; 112: 41-6.

29. Samdani AF, Dawson TM, Dawson VL. Nitric oxide synthase in models of focal ischemia. Stroke 1997; 28: 1283-8.

30. Kawagishi T, Matsuyoshi M, Emoto $M$, et al. Impaired endothelium-dependent vascular responses of retinal and intrarenal arteries in patients with type 2 diabetes. Arterioscler Thromb Vasc Biol 1999; 19: 2509-16.

31. Abiru T, Kamata K, Kasuya Y. Effects of chronic diabetes on vascular responses of basilar artery and aorta from rabbits with alloxan-induced diabetes. Res Commun Chem Pathol Pharmacol 1991; 74: 71-87.

32. Kastrup J, Rorsgaard S, Parving HH, Lassen NA. Impaired autoregulation of cerebral blood flow in long-term type 1 (insulin-dependent) diabetic patients with nephropathy and retinopathy. Clin Physiol 1986; 6: 549-59.

33. Walters M, Muir S, Shah I, Lees K. Effect of perindopril on cerebral vasomotor reactivity in patients with lacunar infarction. Stroke 2004; 35: 1899-902.

34. Pretnar-Oblak J, Sabovic M, Sebestjen M, et al. Influence of atorvastatin treatment on L-arginine cerebrovascular reactivity and flow-mediated dilatation in patients with lacunar infarctions. Stroke 2006; 37: 2540-5.

35. Sterzer P, Meintzschel F, Rosler A, et al. Pravastatin improves cerebral vasomotor reactivity in patients with subcortical small-vessel disease. Stroke 2001; 32: 2817-20.

36. Saczynski JS, Siggurdsson S, Jonsson PV, et al. Glycemic status and brain injury in older individuals: the age gene/ environment susceptibility - Reykjavik study. Diabetes Care 2009; 32: 1608-13.

37. Kozera GM, Dubaniewicz M, Zdrojewski T, et al. SOPKARD Study Group. Cerebral vasomotor reactivity and extent of white matter lesions in middle-aged men with arterial hypertension: a pilot study. Am J Hypertens 2010; 23: 1198-203. 